\title{
Absence of disease related prion protein in neurodegenerative disorders presenting with Parkinson's syndrome
}

Klaus Jendroska, Olaf Hoffmann, Ludwig Schelosky, Andrew J Lees, Werner Poewe, Susan E Daniel

\begin{abstract}
Movement disorders presenting with parkinsonism may share histopathological features with Creutzfeldt-Jakob disease, a spongiform encephalopathy caused by the accumulation of pathological prion protein in brain. To investigate a possible aetiological link between these conditions and Creutzfeldt-Jakob disease, histoblot immunostaining for pathological prion protein was carried out in 90 cases including idiopathic Parkinson's disease, multiple system atrophy, diffuse Lewy body disease, Steele-Richardson-Olszewski syndrome, corticobasal degeneration, and Pick's disease. Pathological prion protein was identified in four controls with Creutzfeldt-Jakob disease but not in any of the other diseases examined. The findings suggest that an aetiological role for prions in these movement disorders is unlikely. Histoblotting provides a useful method for screening large areas of tissue for the presence of pathological prion protein and may be helpful in the differential diagnosis of difficult cases.
\end{abstract}

(F Neurol Neurosurg Psychiatry 1994;57:1249-1251)

The transmissible spongiform encephalopathies comprise a small group of diseases of infectious, hereditary, or sporadic origin characterised by the accumulation of an abnormal isoform of prion protein in the brain. ${ }^{1}$ Neuropathological examination shows spongiform degeneration of the neuropil, severe astrocytic gliosis, and in many, but not all cases, amyloid plaques composed of prion protein. Human prion diseases so far documented include Creutzfeldt-Jakob disease, Gerstmann-Sträussler-Scheinker syndrome, Kuru, and fatal familial insomnia.

By contrast, the cause of most movement disorders remains speculative; a possible relation with Creutzfeldt-Jakob disease, as suggested by some neuropathological features, ${ }^{2}$ has not yet been excluded. Status spongiosus, a coarse microcystic vacuolation of the grey matter is the end stage of spongiform degeneration in prion diseases; it may, however, also occur in Lewy body disease, ${ }^{3}$ Pick's disease, corticobasal degeneration, and Steele-
Richardson-Olszewski syndrome (SE Daniel, personal observations). Furthermore, swollen neurons, an otherwise uncommon form of nerve cell degeneration occurs in CreutzfeldtJakob disease as well as in all of these diseases. $^{2}$

To investigate a putative role for prions in idiopathic Parkinson's disease, diffuse Lewy body disease, Steele-Richardson-Olszewski syndrome, Pick's disease, and corticobasal degeneration we used the novel technique of histoblotting. ${ }^{4}$ Although there is little pathological overlap to suggest a relation between Creutzfeldt-Jakob disease and multiple system atrophy, we examined multiple system atrophy to complete the study of parkinsonian syndromes of unknown aetiology.

\section{Material and methods}

Brains of 90 patients with parkinsonism who had registered during life as brain donors for the UK Parkinson's Disease Society Brain Bank were used for the study. The cases included idiopathic Parkinson's disease (52); multiple system atrophy (17); diffuse Lewy body disease (11); Steele-RichardsonOlszewski syndrome (six); Pick's disease (two); and corticobasal degeneration (two). Tissue from four patients with histologically established Creutzfeldt-Jakob disease were used as positive controls. At necropsy, brains were cut midsagitally with one half frozen at $-70^{\circ} \mathrm{C}$ and the other fixed in $10 \%$ neutral formalin for at least six weeks. Neuropathological diagnosis was made with standard techniques and tissue blocks taken from multiple regions of cerebrum, brain stem, cerebellar hemisphere, and vermis. Sections were stained with haematoxylin and eosin, luxol fast blue-cresyl violet, and a modified Bielschowsky silver impregnation. In selected regions immunocytochemistry for glial fibrillary acidic protein (GFAP, Dako, polyclonal 1:400), Tau (Sigma, monoclonal 1:1000), and ubiquitin (Dako, polyclonal 1:400) was performed with a biotin-streptavidin system. Histoblots were carried out on whole hemispheric sections of the occipital lobe and on sections with disease specific pathology.

Histoblots were performed as described earlier, with some modifications. ${ }^{4}$ Briefly, sections of unfixed frozen tissue cut at $16 \mu \mathrm{m}$ 
thickness were pressed on to nitrocellulose membranes. The membranes were then denatured in guanidine-thiocyanate, rinsed in TBST (150 $\mathrm{mM} \mathrm{NaCl} / 10 \mathrm{mM}$ Tris $\mathrm{HCl}$ $0.05 \%$ Tween $20, \mathrm{pH} 7.8$ ) and blocked in $1 \%$ bovine serum albumin. The antiserum Ro66 was raised in rabbits against hamster prion protein (kindly provided by Dr Prusiner, UC, San Francisco, USA). Incubation with primary antibody, diluted 1:1000 in TBST, was for 18 hours at room temperature. Blots were then washed in TBST and incubated in antirabbit-alkaline phosphatase conjugate (Promega, Madison, MI, USA), diluted 1:5000 in TBST, for one hour at room temperature. Finally, membranes were washed in TBST and developed with Promega reagents. A second set of blots was submerged in digestion buffer $(50 \mu \mathrm{g}$ proteinase $\mathrm{K}$ (Boehrringer) $/ \mathrm{ml}$ in $100 \mathrm{mM} \mathrm{NaCl} / 10 \mathrm{mM}$ Tris $\mathrm{HCl}, \mathrm{pH} 7 \cdot 8$ ) for 15 minutes at $37^{\circ} \mathrm{C}$ for limited proteolysis, and incubated for $30 \mathrm{~min}$ utes in TBST/3 mM phenyl-methyl-sulphonyl fluoride before denaturation. The normal isoform of prion protein is removed under these conditions but staining of pathological prion protein in cases with Creutzfeldt-Jakob disease is not reduced. Chemicals were obtained from Sigma unless stated otherwise. All experiments were carried out in duplicate. Sections from cases of Creutzfeldt-Jakob disease were always included as positive controls.

\section{Results}

Prion protein stained strongly in all four cases of Creutzfeldt-Jakob disease. Staining was throughout the cerebral cortex, most pronounced in the deep layers, and in the subcortical grey nuclei (figure (a)). Due to the diffuse strong staining of the entire cortical ribbon, individual plaques could not be identified.

As prion protein in our cases of Creutzfeldt-Jakob disease was less protease resistant than prion protein in hamster models of prion disease previously examined by histoblots ${ }^{4}$ we reduced the proteolytic conditions and included blots without protease treatment to avoid false negative results due to overdigestion.

By contrast with Creutzfeldt-Jakob disease, there was no immunoreactivity for pathologi-

(a) Immunostaining of pathological prion protein (arrow) in Creutzfeldtfakob disease; (b) absence of staining in Parkinson's disease. $I=$ insular cortex; $P=$ dorsal putamen. cal prion protein before or after protease digestion in whole hemispheric sections of the occipital lobe or in regions with disease specific pathology in any of the cases of movement disorders examined (figure (b)).

\section{Discussion}

Transmissible spongiform encephalopathies are caused by pathological prion protein ${ }^{1}$ that accumulates in grey matter and was clearly shown in cases of Creutzfeldt-Jakob disease we examined. By contrast, examples of Lewy body disease, multiple system atrophy, Steele-Richardson-Olszewski syndrome, Pick's disease, and corticobasal degeneration were negative, thereby excluding a role for prions in the aetiology of these disorders.

The pathological hallmarks of prion diseases comprise neuronal loss with spongiform degeneration and severe astrocytic gliosis. ${ }^{5}$ Some cases of Creutzfeldt-Jakob disease have been described, however, that lack appreciable spongiform change on light microscopical examination ${ }^{6}$ thus making it more difficult to exclude this diagnosis on morphology alone. ${ }^{7}$ It has been suggested that status spongiosus (which denotes the end stage of spongiform degeneration in the prion diseases) may be attributable to hypoxia or other metabolic derangements in the agonal state when it occurs in non-prion diseases. ${ }^{6}$ Alternatively, in Steele-Richardson-Olszewski syndrome, Pick's disease, and corticobasal degeneration heavy cortical involvement with severe nerve cell loss and gliosis may result in status spongiosus (personal observations). The neuronal degeneration in Creutzfeldt-Jakob disease may take the form of swollen cells as well as shrunken neurons. ${ }^{6}$ Swollen nerve cells also occur in idiopathic Parkinson's syndrome, Steele-Richardson-Olszewski syndrome (personal observation), Pick's disease, ${ }^{2}$ and corticobasal degeneration $^{8}$; the significance of this change remains to be elicited.

The novel method of histoblot immunostaining for prion protein is highly sensitive and specific for the detection of pathological prion protein that accumulates in brains of prion diseases. Its specificity for the pathological protease resistant prion protein is enhanced by removing the normal protease sensitive prion protein through controlled enzymatic digestion. Histoblots prove a useful screening method for potentially infectious disease at our Brain Bank. The exclusion of prions as a cause of parkinsonian movement disorders, however, does not of course lead to relaxation of the recommended safety precautions.

We thank Mrs M Lebeck, Mrs L Elliott, and Ms H Sangha We thank Mrs M Lebeck, Mrs L Elliott, and Ms H Sangha for technical assistance and Ms $\mathrm{R}$ Nani for secretarial assisParkinson's Disease Society. Dr Jendroska is funded by a grant from the Ernst Schering Forschungsgesellschaft.

1 Prusiner SB. Molecular biology of prion diseases. Science 1991;252:1515-22.

2 Clark AW, Manz HJ, White CL, et al. Cortical degeneration with swollen chromatolytic neurons: Its relationship to Pick's disease. $₹$ Neuropathol Exp Neurol 1986;45: 268-84. 
3 Hansen LA. A neuropathological subset of Alzheimer's disease with concomitant Lewy body disease and spongiform change. Acta Neuropathol 1989;78:194-201. 4 Taraboulos A, Jendroska K, Serban D, et al. Regiona mapping of prion proteins in brain. Proc Natl Acad Sci USA 1992;89:7620-4.

5 Jakob A. Über eine eigenartige Erkrankung des Zentralnervensystems mit bemerkenswerten anatomischen Befunden (Spastische Pseudosklerose-Encephalomyelopathie mit disseminierten Degenerationsherden). Zeitschrift für die Gesamte Neurologie und Psychiatrie 1921;64:147-228.
6 Masters CL, Gajdusek DC. The spectrum of Creutzfeldt-Jakob disease and the virus-induced spongiform encephalopathies. In: Smith WT, Cavanagh $\mathrm{JB}$, eds. Recent advances in neuropathology-2. Edinburgh: Churchill Livingstone, 1982: 139-63.

7 Tomlinson BE. Ageing and the dementias. In: Adams JH, Duchen LW, eds. Greenfield's Neuropathology. 5th ed. London: Edward Arnold, 1992:1284-410.

8 Rebeiz J, Kolodny EH, Richardson EP. Corticodentatonigral degeneration with neuronal achromasia.
Arch Neurol 1968;18:20-33. 